\title{
The Historical Succession of Cultural Impacts upon South Africa.
}

By Prof. Raymond A. Dart, University of the Witwatersrand, Johannesburg, South Africa.

SINCE their discovery by the ivory trader Adam $S$ Renders (1868) the famous Zimbabwe ruins in Rhodesia have formed the rallying-point around which a fierce and even bitter controversy has raged amongst anthropologists and others. The central point at issue is whether these stately relics owe their existence to an endogenous civilisation, which has since vanished, or to an external and highly advanced culture the impact of which, though powerful, was gradually and ingloriously diminished at a remote historical period.

The conflict which has proceeded about this issue has been valuable in causing suggestive data of considerable magnitude to be placed upon record. It has revealed the existence of a stupendous enterprise in mining of gold, copper, tin, and pigments which involved virtually the whole territory from the Belgian Congo on the north to the Central Transvaal on the south, and from the Kalahari Desert in the west to the Portuguese East African coast in the east. These undertakings were prosecuted with a finesse which never fails to command the respect of modern engineers. Rhodesia, the centre of the mining area, is found at the present time to be pervaded by extensive monumental remains in the form of monoliths, stone circles, and stone buildings, together with vast areas of terraced cultivation. In many instances the buildings reveal a nicety of architecture and a regard for sanitation such as are not characteristic of Southern African natives. Moreover, the ornamentation and objects of phallic worship found in numerous sites have betrayed to many the influence of a people with artistic feeling, and with a complicated theology and religious ritual, who were probably Phœnician, coming from Sabaea in south-eastern Arabia.

Important as the information at our disposal may be, we are far from an exact knowledge in any of the fields involved in this evidence. There has been as yet no systematic anthropological survey of even a portion of the territory involved. In the absence of detailed and precise data, it has been easy for illinformed argument to accumulate and the significant issues to be overwhelmed in a sea of conjecture.

It is at this juncture that the painstaking and tireless investigations of a Trappist monk of the Marianhill Monastery in Natal appear to provide decisive information such as has been so long searched for. Equipped with the knowledge of an artist skilled in reproducing and retouching medieval works of art in the Cathedrals of Cologne, Bonn, and elsewhere, Brother Otto has been copying with infinite patience for some years the Bushman paintings found in the rock shelters of the Kei River Valley, in the eastern portion of the Cape Province. Copies of certain of these he has forwarded to me with notes for the purposes of this article.

Bro. Otto is not the first investigator who has worked in this region. Stow visited a number of the caves here; and another priest, P. M. A. Schweiger, R.M.M., published (Anthropos, igr 3) certain of the paintings which Bro. Otto has since studied more minutely. It has remained, however, for Bro. Otto to reveal the historical significance of these works of art.

NO. 2890 , VOL. II 5$]$
In the first place, Bro. Otto believes he is able to prove that the art of painting was indigenous to this country, and was not introduced from outside. The works which illustrate the beginnings of the art are crude drawings in charcoal, chiefly of animals, and later of naked human forms revealing the well-known Bushman characteristics. Apparently, by experimenting with pigments mixed with the juices of the Euphorbia flora, works were executed with exceedingly fine brush technique. The pigments, of which a considerable variety was utilised, seem finally to have been rendered impervious to the passage of time and the most rigorous climatic exposures by the discovery of the value of oil as a medium, until latterly the finest works were executed indifferently in the recesses of shelters or on the weather-beaten faces of the rocks outside.

These matters are important enough, but a greater human interest attaches to the discovery that, after their technique had become perfected, the Bushman found subjects for artistic exploitation in voyagers who visited their coasts and inland rivers at a period

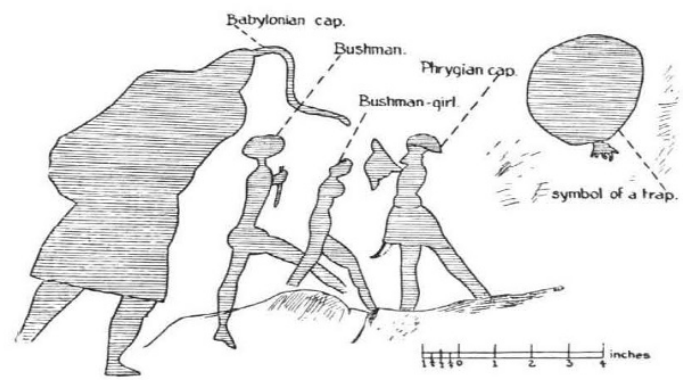

FIG. 1.-Bushman painting in deep red monochrome, in a cave near the confluence of Ngolosa and Kei Rivers. (After Bro. Otto.)

so remote in time that paintings depicting them are sometimes found to be partially covered by an incrustation one-sixteenth of an inch in thickness.

From twenty-eight separate sites over an area twenty miles in length along the Kei River, Bro. Otto has collected more than two hundred and fifty copies of painted groups, and has not omitted, to his knowledge, any detail depicted by these primeval artists within this circuit. From this mine of material he is in a position to provide authoritative information concerning the homeland of these visitant navigators of early times.

A picture from a cave near the confluence of the Ngolosa and Kei Rivers in the Cape Province is represented in Fig. r. Here we find the figures of two naked Bushmen, and of two foreigners-gigantic in the Bushman's estimation, and wearing ancient Asiatic tunics and headgear. The painting depicts a scene in which a piece of clothing is about to be cast over a nude Bush maiden by a bearded man dressed in a Phrygian tunic and cap, and carrying a weapon (sword?). Opposition is expressed in the antagonistic attitude of the naked Bushman, who carries a stick in his hand, while the operations are followed closely by the other massive figure, also clad in a tunic, but 
wearing a cap of Babylonian design. This figure has no weapon, and is presumably that of a merchant captain. Other pictures of similar alien intruders show them to be usually bearded and armed with bows and arrows, shields, and other weapons-swords and javelins, - whereas the Bushman in these old pictures is generally unarmed or is armed only with a stone or a stick. It seems possible from these facts that the Bushman learned the use of the bow from such visitors.

It is amazing to find that the clothing and headgear

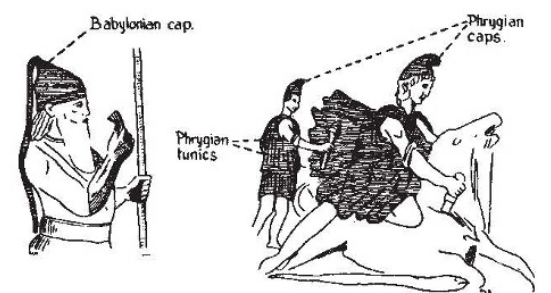

FIGS. 2 and 3.-On the left, figure of Marduk, original in the Berlin Museum. (After Birkner, "Rassen und Völker.") On the right,
Mithras slaying a bull, original in the Louvre, Paris. (After Hochland.)

of the people depicted in this painting have their counterpart upon the bas-reliefs of Babylonia and the ancient paintings and sculptures of the Mediterranean area (see Figs. 2 and 3 ).

It is perhaps equally remarkable that no inferences have been drawn from pictures already published similar to those in the possession of Bro. Otto. More than twenty years ago there appeared in the "Natal Railway Guide" (I903, p. 2 I6) a picture (Fig. 4), photographed in Natal by J. E. Middlebrook, which presented the same striking juxtaposition of naked Bushmen and clothed Asiatics of the Babylonic-Phœnician period. This photograph was reproduced for the purposes of an article by D. Waterston in the Scientific American (I9I5, p. I9I). In the meantime, as mentioned already, another priest, Albert Schweiger, had published (Anthropos, Bd. VIII., I9I3) numerous pictures portraying the presence of clothed foreigners

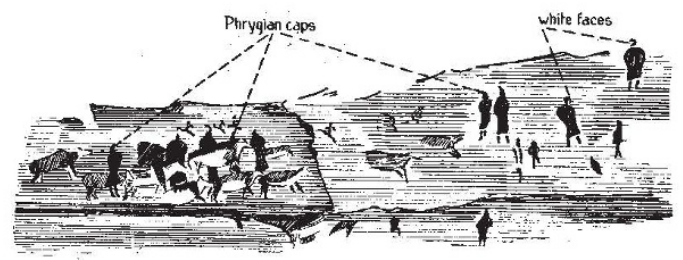

FIG. 4.-Bushman painting from Natal revealing contact of Phonicians with Bushmen. (After photograph from the "Natal Railway Guide," roo3, and The Scientific American.)

which were gathered in the same area as that examined by Bro. Otto. A copy of one of these paintings (Tafel XI.) showing a Babylonian type of cap is shown in Fig. 5 .

Pictures showing clothed foreigners are also to be found in the classical work of Miss Helen Tongue ("Bushman Paintings," Oxford, I909). This author has published many plates of paintings copied in the eastern part of the Orange Free State and Cape Province. Plate XV., No. I02, of her work presents a "procession of men and women dressed in cloaks." The faces of the members of the procession are painted white-a feature of no small significance when it is recalled that Bushmen generally represented themselves and other African natives by means of a black or a scarlet pigment. Bro. Otto's experience agrees with that of Miss Tongue and of J. E. Middlebrook (vide Fig. 4) in finding the features of these alien personages depicted usually by means of a white pigment.

We have seen, then, from the independent evidence of at least four people, that foreigners who were clothed in Phœenician and even Babylonian garb were well known to the aboriginal Bushmen of the Eastern Cape Province, Orange Free State, and Natal. But perhaps the most beautiful reproduction of a Phrygian cap was discovered by Father Krauspenhaar a thousand miles north of this region, in Rhodesia, at Rusapi, which is situated on the Beira-Salisbury railway some two hundred miles inland. Fig. 6 is a drawing of Father Krauspenhaar's copy of this picture.

In a portion of the same area (Barkly East) as that examined by Miss Tongue are many pictures of clothed and capped Phœnician foreigners, some of which have been reproduced in Dr. O. Moszeik's " Malereien der Buschmänner" (Berlin, I9ıo, pp. 6r and 66). Barkly East is situated on a tributary of the Orange River

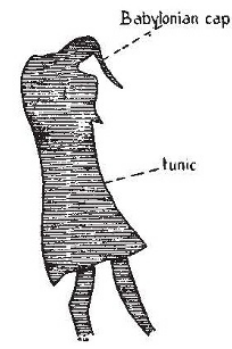

FIG. 5. - Bushman "Nainting from River, Cape Province, depicting a foreigner. (Schweiger.)

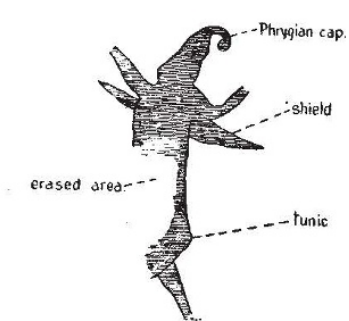

FIG. 6. - Bushman painting in near Rusapi, Rhodesia. (After P. F. Krauspenhaar.) monochrome red from a cave

nearly two hundred miles inland, and consequently we are now in a position to state that the whole of the eastern portion of the African continent for some hundreds of miles inland, which lies between the latitudes of the Zambezi on the north and the Orange and Kei Rivers on the south, was exploited by the oldcolonists, as Bro. Otto terms them, from South-west Asia in remote ancient times. He calls them oldcolonists because he believes he is able to prove conclusively from the paintings that these very ancient voyagers not only visited these territories and carried off their denizens, particularly their women, but also intermarried with them and settled down amongst them, bringing to them novel arts and customs (Fig. 7).

The significance of these observations for the unravelling of the Zimbabwe riddle is not far to seek, for they reveal the unsound nature of Randall MacIver's theory of medieval and even Bantu origin of the ruins, mines, and agricultural terraces south of the Zambesi. The pictorial art of the Bushman has preserved through the lapse of centuries unassailable evidence of the impact of ancient civilisations of the Eastern Mediterranean and Mesopotamian areas upon a Bushman South Africa which betrayed in their day no evidence of Bantu contamination.

One of the supposedly crucial pieces of evidence

$$
\text { NO. } 2890 \text {, VOL. I I } 5 \text { ] }
$$


adduced by MacIver in support of his hypothesis of a medieval Rhodesia, the culture of which was of purely Bantu origin, was the constantly recurring discovery of Chinese porcelain in these ruins. The presence of this ware was rather naturally attributed to Portuguese influence. But the Chinese were navigating the Indian and Pacific oceans in luxurious fashion in the days of Marco Polo, when the Princess Kokáchin went by sea from China to Persia. Nearly three centuries before Marco Polo's time, Alberuni (about A.D. ro3o) records that "The reason why in particular Somanâth (in India) has become so famous is that it is a harbour for seafaring people, and a station for those who went to and fro between Sufâla in the country of the Zanj and China " (E. C. Sachau, Igro, vol. 2, p. I04). Indeed, the timid writer of the Periplus found his way south along the African coast so far as Rhapta in the first century of our era, and relates of Arab captains and agents at that period "who are familiar with the natives and intermarry with them, and who know the whole coast." There is every reason for believing that

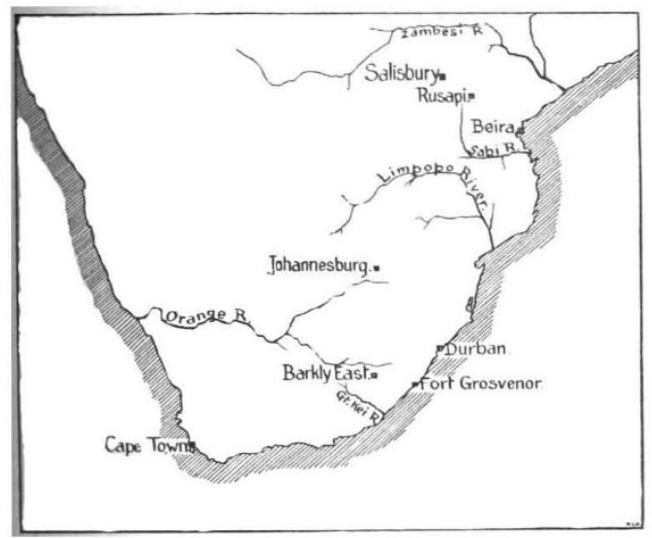

in the early centuries of the Christian era, and perhaps prior thereto, when Chinese arms were pushing far westward upon land, Chinese shipping was contesting with Indian and Arabian vessels the trade of the East African coast, which had already fallen from the hands of Egypt and Mesopotamia and those who brought and carried for these countries.

Fig. 8 is a copy of Miss Helen Tongue's Plate XVIII., No. 27 , of which she states that" the whole appearance of this painting is ancient." The present interest lies in the fact that it portrays a man of light brown complexion, adorned with two necklaces, arrayed in sumptuous apparel, and carrying on his head a peaked Chinese hat. Bro. Otto has also discovered a number of pictures (e.g. Figs. 9 and Io) showing this unexpected type of headpiece. In the light of all these facts it must be recognised that MacIver's hastily drawn conclusions are utterly inadequate to explain the ethnological problems of the southern end of this continent.

That Rhodesia was brought into contact directly with Arabian and Indian agricultural products is shown by the fact that vines, lemons, figs, and cotton, though not indigenous to South-east Africa, are found on the terraced hills of Inyanga in Rhodesia. " Living- stone, Chapman, Burton, Kirk, and all authorities on Zambesia down to the present day have called attention to the great number of plants, fruits, and trees of Indian habitat to be found together on the Rhodesian goldmines area. These are, of course, not indigenous to this country: the now wild Tonge manga, a cotton of Indian origin, not the Tonge cadja, which is indigenous ; also a bean, Cajanus Indicus, known in India as the Dhal Plant; the Indian fig, grown wild; and a tree, matuvi, found elsewhere only in India. There is also the Mahobohobo, which has its habitat only in Southern India and Malaya. In Rhodesia this tree is only found on the area of the prehistoric rock mines, but the vast extent of the country now covered by its forests demonstrates that it arrived in some exceedingly remote time" ("Guide to Rhodesia," r924).

Whether Chinese pottery reached Rhodesia by a European or, as is more likely, by a more direct route past India and Arabia, the discovery of it affords us little light upon what was taking place in Southern Africa long before European and even Indian and Chinese contact was possible; and it is precisely here that the evidence accumulated by Bro. Otto is of premier significance, seeing that it demonstrates an extremely ancient cultural impact upon the aboriginal Bushman.

These remarkable pictures also bring into their proper perspective a series of discoveries of a different but allied nature which have been inadequately appreciated hitherto.

About fifty years ago,

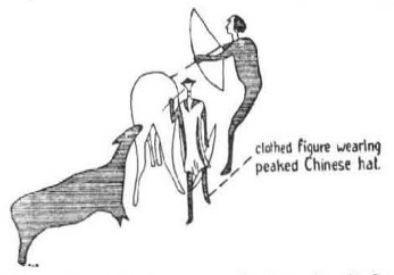

FIG. 8. - Bushman painting in light brown and dark brown, from Magdala, near Barkly East. (After Miss Tongue.)

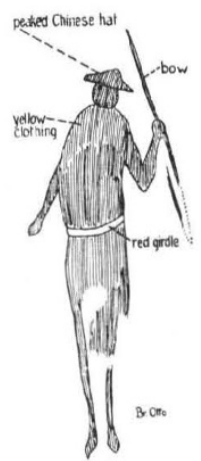

Fig. 9.-Bush man painting on a stone block, Eliweni, Kei River, depicting foreigner.
Mr. Thomas Cook, who is still living in Durban, discovered twenty-eight coins in a calabash at a depth of about six feet, on the site of a native hut, near the beach at Fort Grosvenor in Eastern Pondoland. Many of these were so worn that their inscriptions were illegibleillustrating that they had been much handled-but some, which were legible, were described by Mr. G. F. Hill, of the British Museum, in the Classical Review (of 1897 or 1898). The oldest three coins were of the period of Ptolemy I., II., and IV. respectively (i.e. 304-204 B.C.), and the other coins examined were Roman coins issued between the dates A.D. 296 and $3^{\text {I } 3}$, five of them being struck at Alexandria, two at Antioch in Syria, and one at Cyzicus.

This discovery is not the only one of its kind, for when the monks were building their water reservoir at Marianhill, twenty-six miles from Durban, they found, at a depth of eighteen inches in a recent stratum

$$
\text { NO. 2890, vOL. I I } 5 \text { ] }
$$


of sand and humus on the side of a hill, a Hebraic coin of the reign of Simon Maccabæus (I43-I 36 B.C.), with the inscription "fourth year of the deliverance of Sion" (Anthropos, Bd. V., I909, p. I68).

Now it is conceivable that stray Egyptian, Maccabæan, Syrian, and other coins might percolate even to extreme Southern Africa without any intense cultural movement being afoot; but coins generally signify commerce, and the most cursory examination of any map of Africa south of the Zambezi will show that Palestine and Arabia-those homes of commerce - have left behind very clear evidence of a lengthy contact with this part of the globe. It is by no accident such as might conceivably determine the movement of coins, nor by any philo-Semitic proclivities of the Portuguese, that we find in Portuguese East Africa and the countries adjacent thereto place-names such as Antiocha, Jacobecua, Jacoja, Jacota, Gadsane, Gadzema, Jofane, Gaza, Gizha, Sinoia, Jobo, and the like. The two rivers Sabi and Sabie as well as Lake Sibai, together with Sabia, Sabetsi, Sebaba, Sebakwe, Shebekwe, Shibuto, Shibabara, Chabane, Chiba, Chibi, Chibambala, Chibababa, and so on, owe their names to a people fascinated by the central root Saba, Seba, or Sheba, just as the Dutch have left in South Africa their "fonteins" and "burgs," the English their "Londons" and "Cambridges," and the Scotch their "Dundees" and " Glencoes." So, too, Masibi, Mazibi, Mazibila, Masipe, Mripa, Mriba, and Mareba have an intimate relation with Marib, in the same way as Mocuba, Mokuba, Mkubi, Namoko, Makiki, Muchacha, Machiche, and Machacane recall the Arabian Mocha.

In brief, the themes for the variations provided by hundreds of place-names south of the Zambezi lie in the Asiatic continent, and still await the investigations of specialists in this field. The evidence to be culled from this study will be especially valuable in " dating" and "placing" the different cultural intrusions. Many of the Arabian-names are undoubtedly preKoranic. In addition to names from Western Asia, there are Indian types such as Ricatla, Mandle, and Kande, and variants of the old name of Japan (Zipangu), namely, Chipanga and Chipinga. I have entered into this matter of place-names in some detail because, rich as the field obviously is, I am not aware of any serious study of this sort made hitherto upon this locality.

We have considered already evidence which indicates that, prior to the coming of the European, not only medieval Arabian, but also Indian, Chinese, pre-Koranic Arabian (Himyaritic-Sabaean), Palestinian, Phrygian, Fig. Ir.-Bushman and even Babylonian influences have
painting, from
"Ngolosa" (Kei played a part in moulding the des"Ngolosa" (Kei played a part in moulding the desEgyptian char- Southern Africa. There are not lackacters in clothing (After Schweiger.)

intimate contact with this remote region. There is one picture of Schweiger's from the Kei River Valley (Fig. II), in which the head-dress, clothing, and artistic feeling is positively Egyptian. However, I would have disregarded this picture if $\mathrm{I}$ had not been arrested while in
Marianhill by the persistence or the same Egyptian fashions of head-dress amongst the native women at the present day. The photograph reproduced in Fig. I2 reveals Egyptian characters not only in the head-dress

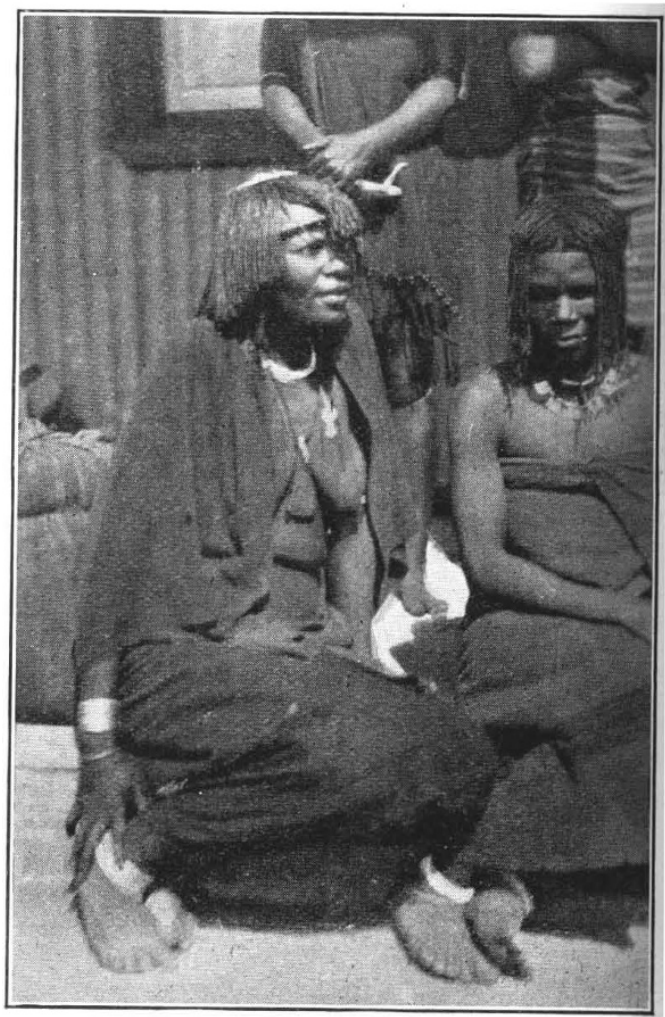

FIG. 12.-Native women, Marianhill, Natal, showing Egyptian characters in head-dress and clothing.

and the head-ring, but also. in the clothing (suspension at the waist, fringe at the lower margin), and even in the features of one woman; the other looks Semitic, but neither is frankly Negroid or Bushmanoid. For comparison with Figs. II and I2, I have reproduced one of the figures in the procession of servants of the Queen Hatshepsu who visited the Land of Punt (Fig. I3).

In this connexion, it will be recalled that Dr. Karl Peters discovered (Keane's "Gold of Ophir") in Rhodesia a figurino of an Egyptian courtier - of the period of Thothmes III. (Dynasty XVIII.)-holding in his hands the scourge of a slave-driver. Further, most authorities concur in believing that the steatopygous Queen of Punt and her daughter portrayed in the spoils of the voyage of the sister of Thothmes III., Queen Hatshepsu's

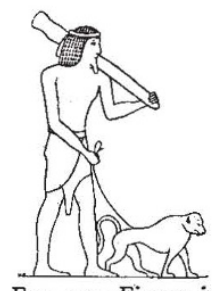

FIG. 13.-Figure in procession of servants, to illus. trate Egyptian head-dress and clothing.

(I50r-I479 B.C.) servants to the divine South-land, was a Bushwoman or closely related to one. Thus Sir Flinders Petrie ("History of Egypt," vol. 2, I899) says, "The strange fatness of the queen has been much speculated upon; whether it was a disease such as elephantiasis, or was natural fat, has been debated; but as her daughter shows much the same tendency of 
curve in the back, it is probably the effect of extreme fat, which was considered a beauty, as in South Africa at present." Rawlinson (Ancient Egypt, r893) is still more emphatic when he states, "She belonged, more probably, to one of the dwarfish tribes of which Africa has so many, as Dokos, Bosjesmen, and others."

The land of Punt is generally supposed to have been south-eastern Arabia or some point along the southern Somali coast; the spices, resins, and incense products being in favour of the former; the giraffes, ivory, cynocephalous apes, and the like speaking for the latter. Frobenius ("Das unbekannte Afrika," r923) has shown in a map the distribution of houses on piles such as were seen by these voyagers to Punt. None such are to be found in Arabia or Somaliland; but they are found on the big rivers of Africa southward from Somaliland. Resins and snuffs have the highest of values amongst the Bush people even in modern times. I do not say that the data are conclusive to prove that God's land, Punt, lay in Africa south of the Zambezi, but the facts are highly suggestive. The products of the country-people, animals, gold, resins, pigments, and the like-were such as this country certainly was affording in plenty at that remote period. At the same time, it is a well-recognised fact that for centuries, perhaps millennia, prior to Queen Hatshepsu, ships had been navigating the Red Sea, the open ocean, and the Persian Gulf between Egypt and Mesopotamia. It is not reasonable then to imagine that the Egyptian queen would render herself a laughing-stock before the civilised world by celebrating in the building and decoration of a new temple as extravagant marvels the products of places near by like the coasts of Arabia and Ethiopia. To fit out an expedition for this remote South-land of Punt was always an epochal event, and was carried out only by the greater Pharaohs in times of peace and prosperity, and was even then worthy of record. Such expeditions are recounted in the times of Sankh-ka-ra (Dynasty XI.) under the nobleman Hannu, of Hatshepsu, of Thothmes III.- the Napoleon of Egyptian history-and of Horemheb (all three of Dynasty XVIII.), and of Rameses III. (Dynasty XX.). It is absurd to believe that these proud names in Egyptian history would reckon trips to little beyond the mouth of the Red Sea as worthy of mention when the equipment of voyages three years in duration were commonplaces in the chronicles of the pigmy court of Solomon. Even in the humdrum days of Herodotus, one circumnavigation of Africa had not been entirely forgotten, for he relates how King Necho's Phœnician servants had accomplished this hardy feat.

His Honour the Administrator of the Transvaal (Prof. Jan H. Hofmeyr) has informed me that the remains of what was presumably an ancient galley were discovered during the laying out of the Maitland Cemetery on the Woltemade flats near Cape Town in the 'nineties. At that time the contact of one end of Africa with the other by navigation was undreamt of, and the significance of finding a boat, one hundred and eighty feet in length, buried six feet underground at a distance of three miles from the present coast-line, was lost on the workmen, who utilised it for firewood. The event at least indicates that the followers of Prince Henry were not the first to anchor in Table Bay.

The continuity of the Atlantic and Indian Oceans around the southern extremity of Africa was customarily portrayed by the ancient cartographers of Greece $(e . g$. Globe of Crates), of Arabia (e.g. Idrisi), and of Europe from Venice to Anglo-Saxon England (vide "Encycl. Britt."). It is difficult to understand how such conceptions could have grown up and persisted in this fashion unless the experiences of ancient voyagers had provided some foundation for them. It is likely that the voyage of Necho's servants was but a repetition of many similar ventures in the storied past. In any case the tale provided by Herodotus is more easily believed when we know that Bushmen from the Zambezi to the south-eastern corner of the continent on the shore-coast and for hundreds of miles inland have recorded in portrait the arrivals and the activities of not merely one but untold numbers of invaders at successive historical epochs.

It is not in the contact of any one people but in the endless procession of emissaries of every great navigating power in the Indian Ocean down this coast that one finds an explanation of the prodigious extent of the early mining industry of Southern Africa. Moreover, it is only in terms of this procession that the physical, anthropological, and ethnological problems of this country can be adequately understood. It is impossible here to do more than direct attention to certain aspects of these intricate but highly fascinating studies. It has already been stated that no exhaustive anthropological survey of the region concerned has been made; but if the urgent necessity for such a survey of the paintings, ruins, terraces and mines, and the nature and richness of its prospective fruits, are indicated, these meagre notes will have been justified.

\section{Biographical Byways. ${ }^{1}$}

\section{By Sir Arthur Schuster, F.R.S.}

\section{r2. Esmatt Effendi.}

$$
\text { I A }
$$
AM not aware that any publication of Esmatt Effendi has ever seen the light of day, but nevertheless my readers, I hope, will agree that his name deserves to be included in this collection of reminiscences. He certainly possessed two essential qualities, enthusiasm and perseverance. I made his acquaintance at Suez, on the evening of May 3, r882, when, on behalf of the Khedive of Egypt, he received a party sent out under the auspices of the

1 Continued from p. $3^{8} 5$.

$$
\text { NO. } 2890 \text {, VOL. I I } 5]
$$

Royal Society to observe the total eclipse of the sun that was to take place on May $x 7$ at Sohag, some way up the Nile. He gave us a very promising account of the local facilities, more especially with regard to bricks and mortar for the foundations on which to place our telescopes; and if his predictions did not come true, and the only brick we saw was that aimed at the head of one of the party by an inhabitant of the village, his intentions were undoubtedly good.

Esmatt Effendi had an ambition to learn something about astronomy, and showed great interest in a 